\title{
REFERENCE WITHOUT COGNITION
}

\author{
Genoveva Martí
}

"Scott is merely a noise or shape conventionally used to designate a certain person."

Bertrand Russell (1911: 163)

1. Names, mechanisms of reference and cognitive fixes

What makes a noise or a squiggle on a piece of paper a name of a thing? The question is important because names are the kinds of expressions we constantly and effortlessly use to say things about objects. Having a name is so important that it is considered to be a universal right according to the Convention of the Rights of the Child endorsed by the UN. ${ }^{1}$

In our society usually parents decide on a name for their child, and they make it official by signing a birth certificate, or by engaging in some more complicated social or religious ceremony. Once the name has been bestowed, the parents start using it to talk about the referent to other people that become members of a chain of communication, a chain that connects the uses of the name to the child. This is the story that the causal-

\footnotetext{
${ }^{1}$ See Hall 2002. Hall reports also that in 1996 a court in Sweden fined a couple for refusing to give a first name to their baby.
} 
historical, or chain of communication picture introduced by Saul Kripke and Keith Donnellan tells us about how uses of names connect to their referents. It is not a story that descriptivists need to reject as contrary to their theory, for it is not. Descriptivism, even old fashioned descriptivism of the kind that Kripke and Donnellan were arguing against, can take the chain of communication on board. From a descriptivist standpoint, whoever bestows a name on an object does so by associating the name to a description. The name arrives to other speakers in the chain of communication when they acquire the description that determines the reference. The transmission of a description is that which, according to descriptivists, makes speakers join as new links in a given chain, and what makes it possible for them to use a name competently to refer to its bearer.

Nevertheless, the descriptivist picture was severely compromised in 1970 by Kripke's and Donnellan's arguments. On the basis of powerful examples and observation of actual usage, Donnellan (1970) argues that a backup of descriptions is neither necessary nor sufficient for a use of a name to reach its referent. Speakers may be at a loss and not possess uniquely identifying attributive information about an object. Yet they can and do use the object's name and they succeed in referring to it. So, the backup of descriptions is not necessary. Kripke's (1970/1980) similar argument came to be known as the ignorance argument.

Moreover, speakers often are misinformed and the only attributions they can make to the referents of the names they use are uniquely satisfied by other objects. Still, when they use a name, the claims they make are about "the right" referent. So, associating uniquely identifying attributes with a name is not sufficient for the use of a name to refer to the satisfier of the attributes. Kripke's argument along similar lines has come to be known as the error argument. 
That names refer without being associated with definite descriptions became one of the emblematic claims of direct reference theory, and this was so because the direct reference reaction against descriptivism was fueled by two fundamental ideas. One is the idea that reference is unmediated, that there are expressions in language that refer without being connected to semantic mechanisms whose role is to determine the referent on each occasion of use. In other words, that some expressions directly refer. From the point of view of direct reference advocates, ordinary proper names are the model of expression that refers without being associated with a search mechanism that selects the referent; in particular, names do not refer via definite descriptions. ${ }^{2}$ The other idea at the heart of the direct reference movement is the idea that referring does not require what Howard Wettstein (1988) has called "a cognitive fix." The rejection of a cognitive fix means that referring with a use of a directly referential expression and, in particular, referring with uses of proper names depends on factors that are out of the cognitive sphere of the speaker. We do not need special cognitive access to things to refer to them. ${ }^{3}$

\footnotetext{
${ }^{2}$ In the past I have argued for the importance of capturing what is essential to directly referential devices by focusing on the absence of semantic mechanisms, an idea that highlights the special status of proper names (and, perhaps, some kind terms). This idea would appear to go against classifying indexicals and demonstratives as directly referential devices. It does. I have argued that putting names and indexicals together in the bag labeled "directly referential terms" obscured the real import of the direct reference revolution. See Martí 1995 and 2003 for discussion.

${ }^{3}$ These two ideas are different. Of course, in the traditional form of descriptivism that Kripke, Donnellan and others were criticizing, both the cognitive fix and the semantic mechanism were two sides of the same coin, for a definite description was taken to provide both the mechanism
} 
Wettstein's point is a negative one; it is about what is not required for an expression to refer to an object. The chain of communication picture advanced by Kripke and Donnellan gives us the positive portion of the story on reference: speakers refer because they are part of a chain of communication that connects their use of a name to previous uses all the way back to the introduction of the name and the referent. It is the fact that speakers are part of the chain, that their use is de facto connected to previous uses, and not what is in their minds that makes their use of a name designate its referent.

The rejection of the cognitive fix and the appeal to the chain of communication goes hand in hand with the strong commitment to externalism that is characteristic of direct reference. One of the lessons of the direct reference revolution against classical Russellian and (perhaps) Fregean descriptivism, an obvious lesson it seems to me, is that what determines the reference of a use of a name, to paraphrase Putnam, "just ain't in the mind."4

However, there has been, as of recent, a reconsideration of accounts of reference that ground reference in cognition, and the idea that a cognitive fix is required to refer is making a comeback. The view is captured by Joseph Almog as follows:

of reference and the cognitive fix required to refer. But the criticisms by direct reference proponents should be separated: that reference occurs without semantic mechanisms is a claim that does not presuppose that those mechanisms are grasped by speakers, and thus that they provide a cognitive fix; on the other hand, the cognitive fix rejected by direct reference proponents could be neither a description nor a similar mechanism.

${ }^{4}$ The original phrase is: "Cut the pie any way you like, 'meanings' just ain't in the head" (Putnam 1973: 704). 
we have some things in mind (an idea also articulable by: things we think about) antecedently to any use of the directly referential device. If we have in mind e.g. Mt. Blanc, and our use of "Mt. Blanc" is the result of that having it in mind, then using "Mt. Blanc" is (technically speaking) a "referential use" and thus, on this view, a directly referential use. There can be no directly referential use without the originary having in mind. ${ }^{5}$

And even a pioneer of direct reference is nowadays inclined to accept that the use of a name to refer must be somehow rooted in some antecedent having in mind of the referent. David Kaplan (2012) has made his the view that referring with the use of a name is parasitic on having in mind (willfully contradicting a declared prior inclination to think otherwise): "In the past, I had the relation between names and having in mind backward. The name rides on the having in mind, not the reverse" (2012: 149).

The new idea of a cognitive fix is quite different from the one Wettstein was arguing against: for one thing, the new cognitive fix is not provided by a description, and so this move is not a return to a straightforward form of descriptivism or Fregeanism. For Frege, at least according to the classical interpretation of Frege, reference starts with concepts acquired by the mind that fix the reference by satisfaction. Neo-cognition advocates, applying some ideas close in spirit to Donnellan's conception of having in mind, defend rather that reference starts with an object which is, so to speak, taken in by the mind: "an object comes to be a subject of discourse because, as in perception, the object reaches the mind of the speaker" (Capuano 2012: 202). And Jessica Pepp (ms) construes and analyzes different aspects of the having in mind relation using perception

\footnotetext{
${ }^{5}$ The quote comes from an abstract for a series of lectures entitled "Referential Mechanics." See Almog 2014 and also Almog 2012.
} 
as the model. ${ }^{6}$ Nevertheless, it seems to me that the move is contrary to the lessons that inspire direct reference theory.

Having the referent in mind is neither necessary nor sufficient for a use of a name to refer to it, much in the way that a backup of definite descriptions is neither necessary nor sufficient for a use of a name to reach its referent. No matter how hard the Martian anthropologist looks into the minds of speakers, he will not find there who they are referring to when they use proper names and, it seems to me, all we need to do in order to reach that conclusion is reflect on how names refer. What I have to say here relies on the original chain of communication picture that Kripke and Donnellan proposed and on some aspects of the theory that Michael Devitt elaborated on the basis of that picture, as I understand them, and I think that my remarks are consistent with their general approach. ${ }^{7}$ My purpose is to explore some aspects of naming and name usage that, in

\footnotetext{
${ }^{6}$ The difference between the classical and the new cognitive fix is reminiscent of the distinction between classically understood senses and senses as interpreted by neo-Fregeans which John McDowell characterizes in terms of the direction of fit. Using perception as the paradigm case by which an object comes to be had in mind, the direction of fit goes from the object to the mind.

${ }^{7}$ See Devitt 1974 and 1981. It should be noted that in his discussion Devitt often appeals to the role of having in mind in naming and referring by using names. In fact, a lot of the arguments in Kaplan 2012 and Almog 2012 are remindful of Devitt's presentation. Nevertheless I think it is rather clear that Devitt is not a neo-cognition advocate. After extensively discussing having in mind in his (1974) he concludes: "This notion was but a stepping stone to our account of designation (by name)" (202) and his account of designation, as it is well known, appeals to "a causal network grounded in an object" (205).
} 
my view, have not been brought sufficiently to the fore, and that highlight that havings in mind do not play the determinant role that neo-cognition advocates afford them. ${ }^{8}$

2. Names, descriptions and havings in mind

We already know from Kripke's and Donnellan's arguments that a speaker can refer when he uses a name even if he does not associate a definite description to the name, and that even if he associates such a description, his use of the name may fail to refer to the satisfier of the description. A definite description is neither necessary nor sufficient for a use of a name to refer to some particular individual.

It seems to me that something similar can be said about having in mind. Suppose that someone enters a room and overhears a conversation in which the name $\mathrm{N}$ is used, becoming convinced that the conversation was about person A, someone she saw leaving the room she was about to enter. She may then join the conversation, start to use $\mathrm{N}$ and continue to use $\mathrm{N}$ thinking that she is saying something about $\mathrm{A}$. Yet, if the conversation relies on an established practice by which $\mathrm{N}$ refers to $\mathrm{B}$, her utterance of $N$ is $P$ is conventionally about $\mathrm{B}$ - and it is very likely that she will eventually be corrected. Of course, the audience may recognize what she has in mind, so she may succeed in communicating something about A. But there are plenty of reasons to treat this as a pragmatic phenomenon. The speaker in question has incorporated a name to

\footnotetext{
${ }^{8}$ I should clarify from the start that the focus here is on what we call proper names in natural language, on their function, and on how they are used to refer. The focus is not on the general phenomenon of reference and on how it occurs.
} 
her vocabulary, and with it the capacity to refer, by virtue of having joined a chain of communication; that she was confused about which chain of communication she joined does not entail she did not do so. Language has its rules; sometimes people keep using words that do not mean what they think they mean.

What seems to me to be the correct explanation of what has happened in that case (an explanation that, I realize, is contested by neo-cognition advocates - but one thing at a time) is the following: our speaker refers to B in spite of having $\mathrm{A}$ in mind. The having in mind is not necessary for the use of the name to refer (since she refers to B without having him in mind) and the having in mind is not sufficient (since she does not refer to A even though she has $\mathrm{A}$ in mind). ${ }^{9}$

Of course, as noted, neo-cognition advocates reject that explanation. In their view it is wrong to presume that our speaker does not have B in mind: she has B in mind, and that's precisely why she refers to B when she uses N. By overhearing and joining the conversation our speaker acquires the having in mind that makes it possible for her to refer to $\mathrm{B}$ using $\mathrm{N}$; a transmission of having in mind has occurred and that is what explains her referring to B when she uses N. As Kaplan puts it: "the transmission of names should be subsumed under the broader notion of being told about an individual. When a proper name in transmitted, we typically have been told about the individual. Thus having in mind has been transmitted, and we take the name to refer to the

\footnotetext{
${ }^{9}$ Obviously, saying that having in mind is not necessary to refer is not tantamount to saying that speakers can refer using a name, or use language for that matter, without having anything at all in mind. If you do not have anything in mind, you are unconscious or dead. In either case you do not refer. I am not defending that speakers can be semantic zombies. We have all kinds of things in mind; I am just denying that the things we have in mind determine what we refer to.
} 
individual we were told about" (2012: 162); "there are two ways to come to have someone in mind. The first way is to do it on our own ... by perceptual or ('direct') acquaintance .... A second way ... is being told about the individual ....This passage of having in mind seems much more fundamental than the passage of names" (148).

So, even though our speaker undeniably has A in mind when she uses N, neocognition advocates argue that she also has B in mind and that she refers to B in virtue of that having-in-mind that she has acquired in joining the conversation. I have some doubts about this explanation.

For one thing, if neo-cognition advocates are right, our speaker has both A and B in mind. Why is it that she refers to B when she uses N, whereas, as some would put it, she only speaker-refers to A? Why is it that the semantic referent of her use of $\mathrm{N}$ is $\mathrm{B}$, not A? In fact, the participants in the conversation may correct our speaker realizing she has A in mind, and hence even they will have A in mind too when they tell our speaker that they are not talking about A but about someone else.

That $\mathrm{N}$ is B's name, that there is a practice in the speakers community that has established $\mathrm{B}$ as the referent, that there is a chain of systematic uses that link $\mathrm{N}$ to $\mathrm{B}$ is what makes the difference. If we are interested, as I think we are as semanticists, in conventional meaning, what we want to focus on is on what makes B the referent of our speaker's use of N, and that, I think, is the fact that her use of the name is appropriately connected to the uses of her co-conversationalists, a connection that depends on objective factors. $^{10}$

\footnotetext{
${ }^{10}$ Typically a use is appropriately connected when the speaker has the intention to use the same name with the same semantic function as the people he acquired it from. But "Madagascar" cases show that the presence of the intention to join the practice is not sufficient. Bianchi (this
} 
The A/B case considered here is somewhat similar to Kaplan's Carnap/Agnew story, so it may be worth thinking about these two cases in parallel. In the Carnap/Agnew story Kaplan is pointing at a picture without seeing it while he utters "That is a picture of one of the greatest philosophers of the $20^{\text {th }}$ century." Kaplan intends to point at a picture of Carnap and he obviously has Carnap in mind, but unbeknownst to him, he is pointing at a picture of Spiro Agnew. The story, as it was used originally by Kaplan, was meant to illustrate a case where a speaker refers to something he does not intend to refer to or, I would add, something he does not have in mind.

The moral of the story was subsequently revised and the case reinterpreted in line with an intentionalist account of the reference of demonstratives. Thus Kent Bach (1992a and 1992b) argued that the speaker has nevertheless the referential intention to refer to the person depicted in the picture he is pointing at, and maybe something similar could be argued in the case of havings in mind: because of her intention to conform to practice, our speaker gets the right object in mind. What is common to this way of explaining the two cases is that both speakers mean to conform to practice: the speaker in the Carnap/Agnew case means to refer to whatever he is demonstrating when he uses "that," and our speaker means to use $\mathrm{N}$ as the people in the conversation that she joins, the people from whom she has acquired the name. So, the job of explaining that they refer, and what they refer to, is done simply by the fact that they rely on and conform to a practice. I do not think we need to add that, by doing so, they are referring

volume) suggests that the intention is not necessary either. Observe nevertheless that the intention of the speaker, if it has any role, does not determine what she refers to. It may contribute, at most, to her joining a practice of usage in which the referent has already been determined. 
to what they intend to refer (as the intentionalist account of demonstratives concludes) or that they are at the receiving end of a transmission of having in mind (thus concluding that the act of referring is parasitic on, explained in terms of, or determined by the having in mind). ${ }^{11,12}$

I take it for granted that a speaker who has an object in mind is thinking about that object. It would be implausible to deny that we are thinking about the things we have in mind. I just do not think it follows that a speaker refers to what she has in mind, or that, if she refers, she must have what she refers to in mind, quite simply because given that there is an established practice, the existence of the practice trumps the other factors.

Neo-cognition advocates may nevertheless counter that the $\mathrm{A} / \mathrm{B}$ case here considered shows at most that having in mind is not sufficient to refer. Our speaker has

\footnotetext{
${ }^{11}$ Referential intentions are fundamentally intentions to conform to practice, and as such they apply equally to uses of names, demonstratives, or any other expression in the language. When a speaker intends to follow a practice, to abide by a rule, it is the rule, and not his intention that does the semantic work. The referential intentions of a speaker do not determine the reference of particular uses of expressions, and so they fall outside of the realm of semantics: "Standardly, when one uses any word in the language of one's community, one does so with the intention that it should carry whatever meaning and reference it has already acquired. This is a fact about the use of all expressions, not about the semantics of any of them" (Soames 2005: 71).

${ }^{12}$ Observe that the A/B case is not similar to Kripke's Smith/Jones case. In the latter when the confused speaker sees Jones and utters "Smith should not be raking leaves" it is natural to describe the speaker as having both Smith and Jones in mind. One of them because he knows him and he uses his name thinking he is talking about him, the other because he is perceiving him. In the A/B case, as in the Carnap/Agnew case, it seems to me that the claims of intentional connection (to Agnew) or of the presence of having in mind (of B) are shakier.
} 
A in mind, undeniably, and if joining the conversation involves a transmission of having in mind, our speaker has B in mind too. Having A in mind is not sufficient for our speaker's use of $\mathrm{N}$ to refer to A, but yet, our speaker ends up referring to something she has in mind after all. Having an object in mind, neo-cognition advocates may insist, is necessary, albeit not sufficient, to refer to it.

But there are situations in which a name is successfully used to refer, even though describing them as cases in which there has been transmission of having in mind is simply contrived. Soames cites an example by Jonathan McKeown-Green:

\begin{abstract}
Suppose, for example, that you know of a certain region in Ireland in which the residents of different towns see to it that there is always exactly one person bearing the name Patrick O'Grady. Learning of this curious fact, you set out to visit the region to interview the different men bearing that name. On entering a pub in a new town, you announce 'I am looking for Patrick O'Grady whom I am willing to pay for an interview for my new book." (Soames 2005: 301) ${ }^{13}$
\end{abstract}

The protagonist of the story refers to Patrick O'Grady, but it is hard to pin down an episode that counts as a transmission of having in mind in the story, and it is hard to

\footnotetext{
${ }^{13}$ In Soames' book the case is used as part of an argument against causal descriptivism and against some versions of the causal-historical theory of reference. The way I interpret the so called causal-historical picture, that names be acquired via a causal-historical transmission is not a requirement for the incorporation of a proper name into one's vocabulary. Nevertheless, the speaker that uses a proper name in a community, no matter how he acquired the name, becomes part of a practice, part of a network of uses. I note that when I say "practice" I do not say "social practice." More on all this below.
} 
count the general information that the speaker possesses, namely, that there is someone by a certain name in every town, as a case of having been told about the referent of that particular use of "Patrick O’Grady."

Observe though, that once the protagonist arrives in the pub, starts using "Patrick O'Grady" and learns how to go about finding the man, the expectation that he soon will meet him, that the referent will soon become significant, makes the case very naturally describable as involving an episode of having in mind, of thinking about an individual. ${ }^{14}$ But reference was there before, and reference was possible because of the speaker's reliance on the function that proper names have as referential devices, and because his use of "Patrick O'Grady" in that pub connects to other uses of the name that refer to the same man.

The McKeown-Green case, I surmise, can be seen as too controversial. ${ }^{15}$ On the one hand, it might be argued that the use of "Patrick O'Grady" is not referential, that the speaker has not really incorporated "Patrick O'Grady" as the name of a particular person into his vocabulary, so that his use is better treated as a quasi non-linguistic use, akin to the use of "champignons au beurre" by someone who does not speak French and has no idea that what the French call "champignons" and "beurre" are mushrooms and butter. I think, however, that even though it is true that the speaker who does not know the meaning of "champignons" and "beurre" clearly does not have these words in her

\footnotetext{
${ }^{14}$ I rely here on Jeshion's "Significance of Names" view, a view according to which the "fundamental function of proper names is to signal or mark an individual's individuality" (2009: 373).

${ }^{15}$ I am very grateful to Jessica Pepp and an anonymous referee for helpful discussions and comments on my discussion of this case.
} 
vocabulary, the fact is that by using "champignons au beurre" simply as a name for a dish, she manages to order the dish and to have it served. Similarly our speaker in Ireland manages to ask about Patrick O'Grady and were he to say something insulting, about a well-known and loved customer of the pub, he would probably be chastised or get in a fight. These things happen, I think, because their uses refer. We manage to say things about things even when we do not have them in mind, precisely because names are a very special part of language and the conditions of possession of names are extremely lenient:

\footnotetext{
The mere possession of a name for an item ... provides a crucial kind of contact with it. One can now ... ask questions, make assertions, and so on that are about that very item. Names, from an epistemic point of view, ask very little of us, but generously provide for our needs. (Wettstein 1989/1991: 175)
}

It might be argued also that the "Patrick O'Grady" case is too unusual, too exceptional to base any conclusion on it. But the Gettier case and the Trolley problem are also based on the description of rather unusual conditions. Unusual cases test theories, that is what they are for.

In any case, I am not sure the "Patrick O'Grady" situation is so unusual. Walking on the street I see plaques on doors with names of people. Every day I walk by the lobby of my building and see names on the mailboxes. When a postal worker asks me if John Sullivan or Anna Calais lives in my building I can answer. He just has a packet with a name. I have just seen a name in a card. They are names and, unless I am massively deceived, they name people. And that is all we need to possess epistemically to say something about them, to inquire about them, to speculate about them if we wish, to 
refer to them. Perhaps neo-cognition advocates want to insist that seeing names on cards, on mailboxes, on letters and on parcels constitutes a transmission of having in mind. I can only say that I do not see a way of providing a plausible story to sustain such a claim.

But surely, neo-cognition advocates may insist, the practice of using "Patrick O'Grady," "John Sullivan" or "Anna Calais" must have arisen somehow. The names must have been introduced, and at the origin of the practice it seems reasonable to suppose someone must have introduced and started to spread a name for a thing she had in mind. It would be preposterous to suppose we can name something without someone having had it in mind at some point or other and having succeeded in using a name to refer to it.

I do not think that this is right. In fact, I think that some times people manage to stick tags on things they do not have in mind. But even if it were true, it would prove very little; in particular, it would not prove that reference is grounded in havings in mind, as we see if we compare that claim to something a descriptivist may want to defend. A descriptivist may insist that, even if users of names can refer without being in possession of a definite description that connects name and bearer, the launching of the name has to be performed via a definite description. The parents must connect the name with a description such as "our newborn girl" and LeVerrier had to connect "Neptune" to "the cause of the anomalies in the orbit of Uranus." Some descriptivists may insist that even cases of naming by ostension should be subsumed under the umbrella of reference fixing via a description.

Suppose that we were to concede all that to the descriptivist. That concession would not make us descriptivists about names. A similar concession to neo-cognition 
advocates would have the same effect as regards the role of havings in mind. A speaker can join a practice of naming, without the transmission of having in mind, much as he can join a practice of naming without the transmission of a description. A speaker can acquire and use a name without having imported the referent into his mind. Of course, neo-cognition advocates could insist that the very acquisition of a name constitutes a transmission of having in mind. But in that case it is hard to see why having in mind should be taken to be more fundamental than acquisition.

Accepting that speakers can refer to what they refer to without having it in mind or without intending to refer to it is in my view crucial if we are to understand language as an institution governed by conventions. Institutions have a life that goes beyond the actions, interactions, mental states, intentions and goings-on in the minds of their members. Surely, the conventions would not arise without those intentions and mental goings-on. But the role of the intentions and mental goings-on is precisely and solely to contribute to the generation of the conventions. In language their role is to contribute to generate practices, to confer a semantic function, and thus the level at which intentions and mental goings-on are operative is not at the level of determining, for instance, the reference of particular uses of a name.

In this regard, there is a partly exegetical issue worth pointing out. Talking about Donnellan's 1966 paper on referential uses of descriptions, where the role of having in mind is undeniably prominent, Almog tells us that "Donnellan unravels the primal semantic relation" (2012: 180); "the mechanism by which the descriptions refer is revelatory of what the direct reference of any expression consists in" (176). There is no denying that having in mind plays for Donnellan a fundamental role in reference. But it is curious, nevertheless, that in his 1970 paper, entirely focused on proper names, 
having in mind appears primarily when Donnellan is offering arguments against the descriptivist attempt to use descriptions such as "the individual I have in mind" as reference determiners. The positive account of how a name is tied to its referent in that paper appeals squarely to the historical picture and there is practically no mention of having in mind in the determination of what a speaker is referring to. In (2012), Kaplan observes how much Russell's and Donnellan's views coincide. The coincidence in their stances is also interesting. In spite of his allegiance to the Principle of Acquaintance and to the view that names are just abbreviations of definite descriptions, in 1911 Russell writes:

In the first place it should be observed that the author of Waverley is not a mere name, like Scott. Scott is merely a noise or shape conventionally used to designate a certain person .... But the author of Waverley is not merely conventionally a name for Scott. (1911: 163)

And in spite of his allegiance to having in mind, Donnellan does not make it the centerpiece in the one article devoted to reflect on common, run of the mill (and nonempty) uses of proper names.

Both authors afford epistemological considerations a central role. Yet, a less visible aspect of them emerges at times, putting forward purely semantic considerations about the role of proper names in natural language that are entirely independent of their official, epistemically oriented views.

In my view, what is required for a sound or a squiggle to be a name of a thing is that a practice be established. So called singular acts of reference may be singular acts of thinking about an object. But thinking about an object is not the same as referring to it 
using a name. A name for a thing is part of a language, and as such it has to be embedded in a pattern of systematic use. And establishing the practice requires success in making people use a name to refer to a particular thing. The success may be unintentional. There is a boy at school whose given name is "Ivan" but my son, by mistake, started to call him "Max." His friends followed suit and nowadays even Ivan's parents call him "Max." This may happen because the person making the mistake is funny or popular or is a trend-setter. In the case of "Madagascar," the explorers also made a mistake, but because of their authority, their political power, or the fact that they drew maps and put names on them, eventually the mistake became the rule. Success in creating a linguistic practice is sometimes a matter of politics.

\section{Naming and using names}

Using a name requires being part of a practice, and bestowing a name consists in succeeding in launching a practice. Thinking of naming from this perspective has some consequences.

First, we should not think that bestowing a name is an act; it is a process. It requires success in launching a practice, and launching practices is not something that occurs instantly. "Madagascar" became the name of the island and "Max" became Ivan's nickname. It did not happen in a specific and circumscribed "act of naming."

It is common to put in place mechanisms that make the process less uncertain. In our society parents or some relatives have the recognized authority - and apparently also the obligation - to choose children's names, and the rest of society abides. In many cultures 
some kind of dubbing ceremony is performed. But what those mechanisms do is underwrite and secure the launching of a practice. ${ }^{16}$

The fact that the idealized picture of naming presented by Donnellan and Kripke focuses on the very simple cases where there is a dubbing ceremony should not distract us from the variety of cases in which the process of introducing a name in a language is considerably more complex; nor should it make us think that there is some abnormality or some essential difference between the simplified cases and more complex instances like the "Madagascar" case, where according to the semanticist's story there was a transfer of a practice and no official dubbing, or at least no official dubbing of the island.

There may not be a point at which a name becomes a name of a thing, and the process may have some grey areas. In cases like the "Madagascar" case, there may be uses for which it makes no sense to insist in determining what that particular use refers to, the island or the mainland. Asking "at what point did 'Madagascar' become the

\footnotetext{
${ }^{16}$ But what about the case in which a name is inscribed on the birth certificate of a baby and never used again? Cases like this, in which a bestowed name is never used to talk about an individual or even to summon him in thought, although rare, have occurred. Besides, nothing seems to make these cases intrinsically impossible, and the inclination to say that upon finding the birth certificate we found out, at least, $a$ name (the given name) of the individual is justified. But, it seems to me, the inclination is there precisely because inscribing a name on a birth certificate is part of the accepted conventional mechanism that secures the launching of a practice. If the rare cases became the norm, if inscribed names were typically never used at all, the conventional mechanism would break down. As Russell said: “A man's name is what he is called" (1911: 163).
} 
name of the island?" may make as much sense as asking "At what point did the baby grow up?" or "At what point did the sick person become healthy?"

That there are grey areas, periods at which it is not clear from the point of view of the semanticist what to answer to the question 'Does this particular use of 'Madagascar' refer to the mainland or to the island?" is to be expected. The existence of grey areas entails a degree of indeterminacy. But the recognition of grey areas is not an invitation to conclude that everything is mushy, that there are no facts of the matter: there is no question that "Madagascar" now in our community refers to the island.

The kinds of cases where an error gives rise to a practice are treated by Devitt (1981) and by Devitt and Sterelny (1999) as multiple grounding. Antonio Rauti (2012) has argued that multiple grounding threatens the stability of reference. If every mistake has to be seen as a case of partial designation in which the use designates in part the conventional referent and in part another object, I think that Rauti is right. But we do not have to introduce partial designation if we are ready to accept some indeterminacy. Simply put, some mistakes catch and some do not. The mistakes that do not catch, do not generate chains, do not establish stable practices, which brings us to the second reflection.

Whether an event counts as the origin of a chain of communication should be ascertained post facto. The issue here is not just an epistemic matter: I do not think that a set of conditions determine, at the moment of occurrence of an event, whether the event in question will constitute the origin of a chain of communication. People may get confused, start using a name for something that it does not name, and for any or all of a myriad of factors the practice may stabilize. If so, we have a successful process of introduction and a systematic practice, but there may be nothing intrinsic to the original 
uses determining the success. I think that in his criticism of Devitt, Rauti errs in looking for the intrinsic features of the "act" of introduction or the "act" of re-grounding that distinguishes it from mere confusions and mistakes. ${ }^{17}$ There are all kinds of factors that contribute to success (or failure) in bestowing a name, in establishing a practice and maintaining it. The process of introducing a name is rather volatile. Many things need to be in place, potential misunderstandings have to be averted, and there can be a lot of instability in the initial conditions. In this regard, naming shares a lot of features with processes in which there is instability of initial conditions. Highly unstable initial conditions may make it impossible to describe a process in terms of necessary and sufficient conditions, and that may be the case even if the process is deterministic.

Not one single factor or determinate collection of factors is generally the key to successful naming. Havings in mind, intentions, exploitation of clues, pointings and describings play an important role. But they are each of them just that: contributing factors. The fact that the speaker has an object in mind when she proposes to call something by a name surely must play an important role in the success of the event. So does the fact that she intends that object to be the object named, that her audience interpret her intention and that they all focus on the same object. And so does the fact that the description the speaker uses, if she uses a description, does apply to that object.

\footnotetext{
${ }^{17}$ I think he errs also in the features he focuses on. According to Rauti the re-grounder is characterized by her normative stance. She does not defer to previous practice. But reflection on cases such as the "Madagascar" one cast doubt on this diagnosis. The explorers after all were deferential to the use that the natives made of "Madagascar," they may have been disposed to be corrected, and they did not see themselves as grounders, trend-setters or initiators of a practice.
} 
But what all these factors do is this: help the naming succeed. They do not determine what is named.

Similarly, other factors clearly play the role of psychological aids. The mental files John Perry, François Recanati and others talk about contain not only descriptive information ("was wearing a red sweater") but also images, memories of situations we can bring to our mind and other memories that we cannot bring up at will, like the sensation a scent, the way someone smells, produces on us. All those factors play a very important psychological role but they are not reference determiners.

In many an occasion, the different factors may pull in different directions, making a prediction impossible as to what will be finally the thing named by a name. But typically, things fall into place. The descriptions we use apply to "the right" object; we name the object we intend to name and in subsequent uses we use a name to refer to the object we intend to refer to; and we usually refer to things we have in mind. That speakers often are in possession of an identifying description does not make names descriptive. That speakers typically intend to refer to the bearer of the name they use does not mean that intentions determine the reference of uses of names. That speakers often have in mind the person they refer to when they use names does not mean that having in mind is required for a use of a name to refer.

I acknowledge that this explanation is vulnerable to the "magic" objection. If describing, having in mind, intending and recognizing intentions are dispensable, what makes names name? Does it happen by magic?

It does not happen by magic, but it happens because of a conjunction of accidents, like everything that has an evolutionary explanation. Let us forget about names for the moment and focus on pointing. As Wittgenstein told us, there is nothing intrinsic to the 
act of pointing that would tell us that the salient thing that is right in front of my index finger is the thing I am pointing at. The same gesture is compatible with it being the thing that intersects the line that starts at the tip of my finger and goes perpendicular to the sky. I point at a dress in a store window. Why do you look at the dress and not at the clouds? The explanation is, very likely, evolutionary, having to do with predators and survival. If a group of cavemen were pointing their fingers in the direction of a fierce predator, the companions whose attention was drawn to the front survived. Those who looked up at the sky or turned around to look backwards did not. The survivors passed the art of pointing as we conceive it to the next generation.

When I point at the dress and I say "too short," you will interpret my utterance as being about the dress just because of those little accidents that happened in the story of pointing. And, as regards names, one is unavoidably reminded of Ruth Barcan Marcus' dictum: "names are the long finger of ostension." 18

The capacity to use names is the capacity to use a piece of the world (a sound or a squiggle) as a representative of another piece of the world and the explanation of how names function may be similar to the explanation of how raising your finger in a certain way constitutes pointing at something and has the effect on people that it has. Perry (2006) speculates that cave dwellers invented names to call their children to dinner.

\footnotetext{
${ }^{18}$ I have been told that Ruth Barcan Marcus first uttered her famous dictum during a discussion about the fact that new theories of reference, unlike descriptivism, did not have an explanation of the mechanism of reference. If names are "long fingers of ostension," the search for a mechanism of reference to replace senses or descriptive contents is misguided. See Marcus
} 1993a: 203. 
A final reflection is, I think, extremely important: that naming is success in establishing a practice does not entail that the practice in question is social and, in fact, I think it would be a mistake to think of the practice in question as intrinsically social. ${ }^{19}$

It is true that even Kripke often stresses the social character of language when he argues against the individualistic picture that we get from descriptivism: "In general our reference depends not just on what we think ourselves, but on other people in the community." (1970/1980: 95). And there is no denying that language is in fact a social institution and that the chain of communication is typically a social chain in which different members of the community and different generations of members participate.

But it seems to me that the social aspect is also a travel companion of the phenomenon and it is not to the essence of it. Although it is de facto unlikely, there should be nothing conceptually preventing a lone agent, a Robinson Crusoe, left on an island before he acquired any language at all, from inventing a language, using names for things, talking to himself and writing his memoirs (even without the hope that they will ever be read or understood by anyone else). ${ }^{20}$ When that lone speaker uses day after day "Charlie," the name he gave to his pet iguana, he is not part of a community of

\footnotetext{
${ }^{19}$ Contra Wettstein 2004.

${ }^{20}$ As Tyler Burge has stressed: "Language is social in that interaction with other persons is psychologically necessary to learn language. Some philosophers have made the further claim that there is some conceptually necessary relation between learning or having a language and being in a community. I do not accept this view. I assume only that it is a psychologically important fact that we cannot learn language alone" (1989: 175). Often, Burge's externalist, anti-individualistic arguments have mistakenly been interpreted as an endorsement of the essentially social character of thought. See also footnote 3 (188) in that paper for clarification of this point.
} 
users, and he is not part of a social practice. Yet, he is engaging in a systematic practice. He is not part of a community of users, but his uses of "Charlie" are part of a community of uses.

Of course, the core issue here is not whether a lone speaker can name and use names. The crucial point is that there has to be a chain of communication even for a single speaker; there has to be a connection between use and use for it to be the case that the speaker speaks a language that contains proper names.

Socially or individually, for a sound to be the name of something, there has to be a pattern of repeated, systematic use. There has to be a connection between use and use, a chain of uses. The links in the chain are not people, they are not users of the name; they are uses of the name. ${ }^{21}$

The insistence on the social character of linguistic practices that Wettstein and even Kripke highlight may make us lose sight of the fact that the main feature we are after is

\footnotetext{
${ }^{21}$ Does this entail that there can be no one-use devices to refer? Referential uses of definite descriptions do not fit the pattern of systematic use, but they still refer. I think that referential uses of definite descriptions are very similar to names - and I think so, in part, because I think that a proper understanding of referential uses would lead us to see that having in mind is not to the essence (I have argued for this in my 2008). Ruth Barcan Marcus called referential uses of definite descriptions throw away names and she also referred to them as discardable tags (1993b: 106). Sometimes they are called ephemeral names. But they are not proper names with the standard function that a proper name has in our language, precisely because they are oneuse. In cases where the practice jells, for instance if we start using "the man drinking a martini" to keep talking about the man at the party, then they become names (they grow capitals, to put it in Marcus' terms); but then the uses are not referential uses of definite descriptions.
} 
not that practices, naming practices in particular, are social, but rather that they must be socializable.

They are socializable because, even if we have just one speaker, the pattern of systematic use is objective. It does not matter whether a new and connected use is a use by this speaker or by someone else. If the practice were not socializable, if it was impossible for someone else to join the practice, if there were no objective, third person fact about whether two uses of a name were connected, then we would have the situation that Wittgenstein envisages when he thinks about what happens when you do not have, cannot have, connected uses. Any use is like a new introduction, and then whatever seems right to the speaker is right.

This picture of what it is to introduce a name and use it is, I believe, just what the so-called causal-historical picture is about. My purpose here has been to point out some aspects of the approach that in my view are not sufficiently considered. One of them is that the approach is entirely alien to the view that having in mind grounds reference. ${ }^{22}$

\footnotetext{
${ }^{22}$ Different versions of this paper were given at the SPR Conference, Donosti 2011, and in 2012 at the Parma Reference Workshop, the Conference of the SIFA held in Alghero, the London Reference Workshop held at King's College, and the Logos Seminar. I am grateful to the audiences for their comments. I am especially grateful to Andrea Bianchi, Michael Devitt and Jessica Pepp for helpful discussions and to an anonymous referee for their comments. The research for this paper has been partly funded by the Spanish MICINN, under grants 2011-2014 FFI25626 and Consolider-Ingenio 2010 (CSD2009-0056), and the European Commission's Seventh Framework Programme FP7/2007-2013 under grant agreement FP7-238128. I acknowledge also the support of the AGAUR of the Generalitat de Catalunya (SGR 20091077).
} 
References

Almog, J. 2012. "Referential Uses and the Foundations of Direct Reference." In J.

Almog and P. Leonardi, eds., Having in Mind: The Philosophy of Keith Donnellan.

Oxford: Oxford University Press.

Almog, J. 2014. Referential Mechanics: Direct Reference and the Foundations of Semantics. Oxford: Oxford University Press.

Bach K. 1992a. "Paving the road to reference." Philosophical Studies 67: 295-300. 1992b. "Intentions and Demonstrations." Analysis 52: 140-46.

Burge, T. 1989. “Wherein Is Language Social?” In A. George, ed., Reflections on Chomsky. Oxford: Blackwell.

Capuano, A. 2012. "From having in mind to direct reference." In W.P. Kabasenche, M.

O’Rourke, and M.H. Slater, eds., Reference and Referring. Cambridge, Mass.: MIT Press.

Devitt, M. 1974. “Singular Terms.” Journal of Philosophy 71: 183-205. 1981. Designation. New York: Columbia University Press.

Devitt, M. and Sterelny, K. 1999. Language and Reality. An Introduction to the Philosophy of Language. Second Edition. Oxford: Blackwell Publishers.

Donnellan, K. 1966. "Reference and Definite Descriptions." Philosophical Review 75: 281-304.

Donnellan, K. 1970. "Proper Names and Identifying Descriptions." Synthese 21: 33558. 
Hall, D.G. 2002. "Semantics and the Acquisition of Proper Names.” In R. Jackendoff, P. Bloom, and K. Wynn, eds., Language, Logic and Concepts. Cambridge, Mass.: MIT Press.

Jeshion, R. 2009. “The Significance of Names.” Mind and Language 24: 372-405.

Kaplan, D. 2012. “An Idea of Donnellan.” In J. Almog and P. Leonardi, eds., Having in Mind: The Philosophy of Keith Donnellan. Oxford: Oxford University Press.

Kripke, S. 1970/1980. Naming and Necessity. Cambridge, Mass.: Harvard University Press.

Marcus, R.B. 1993a. "Possibilia and Possible Worlds." Reprinted in her Modalities.

New York, Oxford University Press. Originally published in Grazer Philosophische Studien 25/26 (1985/86): 107-33. 1993b. "Does the Principle of Substitutivity Rest on a Mistake?" Reprinted in her Modalities. New York: Oxford University Press. Originally published in A.R. Anderson, R. Martin and R.B. Marcus, eds., The Logical Enterprise. New Haven: Yale University Press, 1975.

Martí, G. 1995. “The Essence of Genuine Reference.” Journal of Philosophical Logic 24: $275-89$. . 2003. "The Question of Rigidity in New Theories of Reference.” Noûs 37: 16179. 2008. “Direct Reference and Definite Descriptions.” Dialectica 62: 43-57.

Pepp, J. ms. "Rethinking Reference."

Perry, J. 2006. “Re-seducing Saint Howard.” Philosophical Books 47: 34-39.

Putnam, H. 1973. “Meaning and Reference.” Journal of Philosophy 70: 699-711. 
Rauti, A. 2012. "Multiple Groundings and Deference.” Philosophical Quarterly 62: 317-36.

Russell, B. 1911. "Knowledge by Acquaintance and Knowledge by Description”. Proceedings of the Aristotelian Society, 11: 108-28. Reprinted in his Mysticism and Logic. Totowa, New Jersey: Barnes and Noble, 1976.

Soames, S. 2005. Reference and Description. Princeton: Princeton University Press.

Wettstein, H. 1988. "Cognitive Significance Without Cognitive Content.” Mind 97: 128. . 1991. "Turning the Tables on Frege, or How Is It that 'Hesperus is Hesperus' Is Trivial?" Reprinted in his Has Semantics Rested on a Mistake? Stanford: Stanford University Press. Originally published in Philosophical Perspectives 3 (1989): 317 39. 2004. The Magic Prism: An Essay in the Philosophy of Language. Oxford: Oxford University Press. 